\title{
Vulnerability assessment towards tsunami threats using multisensoral remote sensing data
}

\author{
Hannes Taubenböck* a, b, Michael Wurm ${ }^{\mathrm{a}, \mathrm{b}}$, Joachim Post ${ }^{\mathrm{a}}$, Achim Roth ${ }^{\mathrm{a}}$, Günter Strunz ${ }^{\mathrm{a}}$, Stefan \\ Dech $^{\mathrm{a}, \mathrm{b}}$ \\ ${ }^{\mathrm{a}}$ German Remote Sensing Data Center (DFD), German Aerospace Center (DLR), Oberpfaffenhofen, \\ 82234 Wessling, Germany \\ ${ }^{\mathrm{b} J u l i u s-M a x i m i l i a n s-U n i v e r s i t a ̈ t ~ W u ̈ r z b u r g, ~ D e p a r t m e n t ~ o f ~ G e o g r a p h y, ~ A m ~ H u b l a n d, ~}$ \\ 97074 Würzburg, Germany
}

\begin{abstract}
The occurrence of a tsunami, a set of oceans waves caused by any large, abrupt disturbance of the sea surface, hitting a vulnerable system on land can cause massive loss of life, destruction of coastal infrastructure and disruption of economic activity. Vulnerability assessment and risk modelling are important components for an effective end-to-end hazard early warning system and therefore contribute significantly to disaster risk reduction. The focus of this study is on the capabilities and synergistic usage of multisensoral remotely sensed data to contribute to these complex tasks. We use medium and high resolution optical satellite data (Landsat and Ikonos), high resolution radar data from TerraSAR-X as well as a digital elevation model to provide multiple products for the assessment of spatial vulnerability in case of a tsunami impact on the heterogeneous and highly structured coastal urban area of Padang, Indonesia. Results include physical indicators like dimension and location of urbanization, quantification of potentially affected buildings, the identification of safe areas as well as a time-dependent population assessment.
\end{abstract}

Keywords: Risk and vulnerability assessment, remote sensing, change detection, population estimation, tsunami hazard

\section{INTRODUCTION}

Vulnerability assessment and risk modelling are important components for an effective end-to-end hazard early warning system and therefore contribute significantly to disaster risk reduction. The knowledge about elements at risk, their susceptibility, coping, and adaptation mechanisms is a pre-condition for the setup of people centred warning structures, local specific evacuation planning and recovery policy planning. Especially Indonesia has recently been struck by a series of major earthquakes and arising tsunamis that have largely affected cities: the 2004 tsunami and earthquakes (devastating the cities of Banda Aceh and Meulaboh) and the 2006 central Java earthquake (impacting the Yogyakarta region) with an ensuing tsunami (Leitmann, 2007). The dimension of the 2004 tsunami disaster claiming nearly 275,000 lives and destroying billions of dollars' worth of property (Barber, 2005) reminded the world, to be more proactive in developing ways to reduce their impact.

The work presented here is embedded in the Numerical Last Mile Tsunami Early Warning and Evacuation Information System (Last-Mile) project (Birkmann et al., 2008; Taubenböck et al., in press; www.last-mile-evacuation.de). The term "Last-Mile" is understood as synonym for the immediate coastal area, where a potential tsunami wave piles up and eventually hits the vulnerable system on land. The project focuses on the urban coastal hinterland of the city of Padang, West Sumatra, Indonesia, which has been indicated as one of the most plausible localities for a tsunami of disastrous proportions in the near future (Borrero et al., 2006). Padang is the capital city of the Sumatera Barat province (West Sumatra), and with almost one million inhabitants the third largest city on the island Sumatra, Indonesia. It is located directly on the coast and partially sited beneath the sea level, and thus, is located in a zone of extreme risk to severe earthquakes and potential triggered tsunamis. Off the coast of Padang, the Sunda Arc marks an active convergent plate boundary. According to the catalogue prepared for tsunamis in the Indian Ocean, which includes about ninety tsunamis, $80 \%$ of the tsunamis are from Sunda arc region, where on an average, tsunamis are generated once in three years

*hannes.taubenboeck@dlr.de; phone +49 (0)8153 28-2480; fax +49 (0)8153 28-1445;

http://www.dlr.de/caf/desktopdefault.aspx/tabid-4937/8208 read-13549/

Remote Sensing for Environmental Monitoring, GIS Applications, and Geology IX, edited by Ulrich Michel, Daniel L. Civco, Proc. of SPIE Vol. 7478, 74781J · — 2009 SPIE · CCC code: 0277-786X/09/\$18 · doi: 10.1117/12.830370 
(Rastogi \& Jaiswal, 2006). Padang features supra-regional relevance with an international airport, a port as well as binding to the rail network. Furthermore, the city possesses an important economical role for the coastal region and the mountainous back-country. The multi-faceted functions of the large city are also reflected in a very heterogeneous physical urban appearance.

In comparison to most studies the Last-Mile project focuses on the development of a tsunami early warning information system at high-end geometric and thematic detail. Overall the project aims to analyze and identify risk based on the development of hazard scenarios and the assessment of vulnerability of the current system. Vulnerability itself is considered as a configuration and interaction of physical, demographic, social, economic, environmental and political exposed and susceptible elements as well as coping capacities of these elements (e.g. social groups, infrastructures, economic sectors). Furthermore, the Last-Mile project tries to incorporate various scientific research fields - engineering, remote sensing and social sciences - to cover manifold perspectives for tsunami early warning (Taubenböck et al, in press). This current study focuses on one perspective of the interdisciplinary research project: We analyze the capabilities of multisensoral remotely sensed data and corresponding methods to provide high-end geometric and thematic information on the vulnerability of the coastal urban system of Padang, Indonesia. We use high and medium resolution optical satellite data (Ikonos and Landsat), high resolution radar data from TerraSAR-X as well as a digital elevation model to provide multiple products on the heterogeneous and highly structured coastal urban area of Padang, Indonesia, The main research question in this study is "which information can multisensoral remote sensing data and corresponding methods provide to support risk and vulnerability assessment?"

\section{DATA SETS}

Different satellite images of settlements provide different abstractions of the physical built-up environment. We use manifold remotely sensed data sets to provide a broad overview on the capabilities to support risk and vulnerability assessment in urban areas: For consistent monitoring of spatial urbanization processes we use multisensoral and multitemporal remotely sensed data from the optical Landsat system as well as from the German radar sensor TerraSAR$\mathrm{X}$. The multitemporal medium resolution satellite data from the Landsat sensors (data available from the Thematic Mapper 1989 and Enhanced Thematic Mapper 2000) are utilized. With its field of view of $185 \mathrm{~km}$ the satellites are able to survey large areas with 7 multispectral bands and a maximum of 15 meter geometric resolution. The chosen level of spatial resolution with Landsat features is not with microscopic detail, but enables to classify the urban footprint in its correct dimension. Due to technical problems of Landsat ETM+, continuously monitoring of urbanization processes to date needs new data sources. Therefore we choose the active TerraSAR-X sensor, which is capable of acquiring data at day and night, independent of weather or environmental conditions. Hence, SAR data is more reliably available than optical imagery. Moreover, urban environments feature a more constant and specific behavior and appearance in radar data compared to the spectral characteristics of built-up areas in optical images. In SAR data, settlements appear as clusters of direct backscattering centers - forming bright signal returns - and dark shadow regions. TerraSAR-X provides different modes and incidence angles to scan the earths' surface. Available modes are ScanSAR (with a swath of 100km and an azimuth resolution of $16 \mathrm{~m})$, Stripmap $(30 \mathrm{~km} ; 3 \mathrm{~m})$ and SpotLight $(10 \mathrm{~km} ; 1 \mathrm{~m})$ (Herrmann \& Bottero 2007) (Figure 1d). Thus, the technical specifications enable coverage of the metropolitan area of Padang as well as the capability to analyze extended time series on city level.

Furthermore we incorporate the capabilities of high resolution optical satellite data like Ikonos imagery to assess risk and vulnerability. These data feature a geometric quality of $1 \mathrm{~m}$ for the panchromatic band, $4 \mathrm{~m}$ multispectral, and $1 \mathrm{~m}$ pansharpened and four spectral bands (blue, green, red, nir). The data set can be turned into detailed information defining the small-scale urban landscape at individual building level. Figure 1a and $1 \mathrm{~b}$ show the diverse heterogeneous structure and the local differences in urban morphology of the coastal city Padang, West Sumatra, Indonesia. The urban structure is defined by the heterogeneous physical alignment and characteristics of buildings, streets and open spaces. In general, as seen in the comparison of figure $1 \mathrm{~b}$ and $\mathrm{c}$ the urban structure can be understood at different levels of spatial resolution. On city level the alignment of buildings, streets and open spaces characterizes the structure (Figure 1b), while on block level the physical structure is also reflected in a higher degree of spatial and thematic detail, for example, building types are defined by height, size, or roof type (Figure 1c). Also available is a digital surface and digital terrain model (Intermap, 2007). 


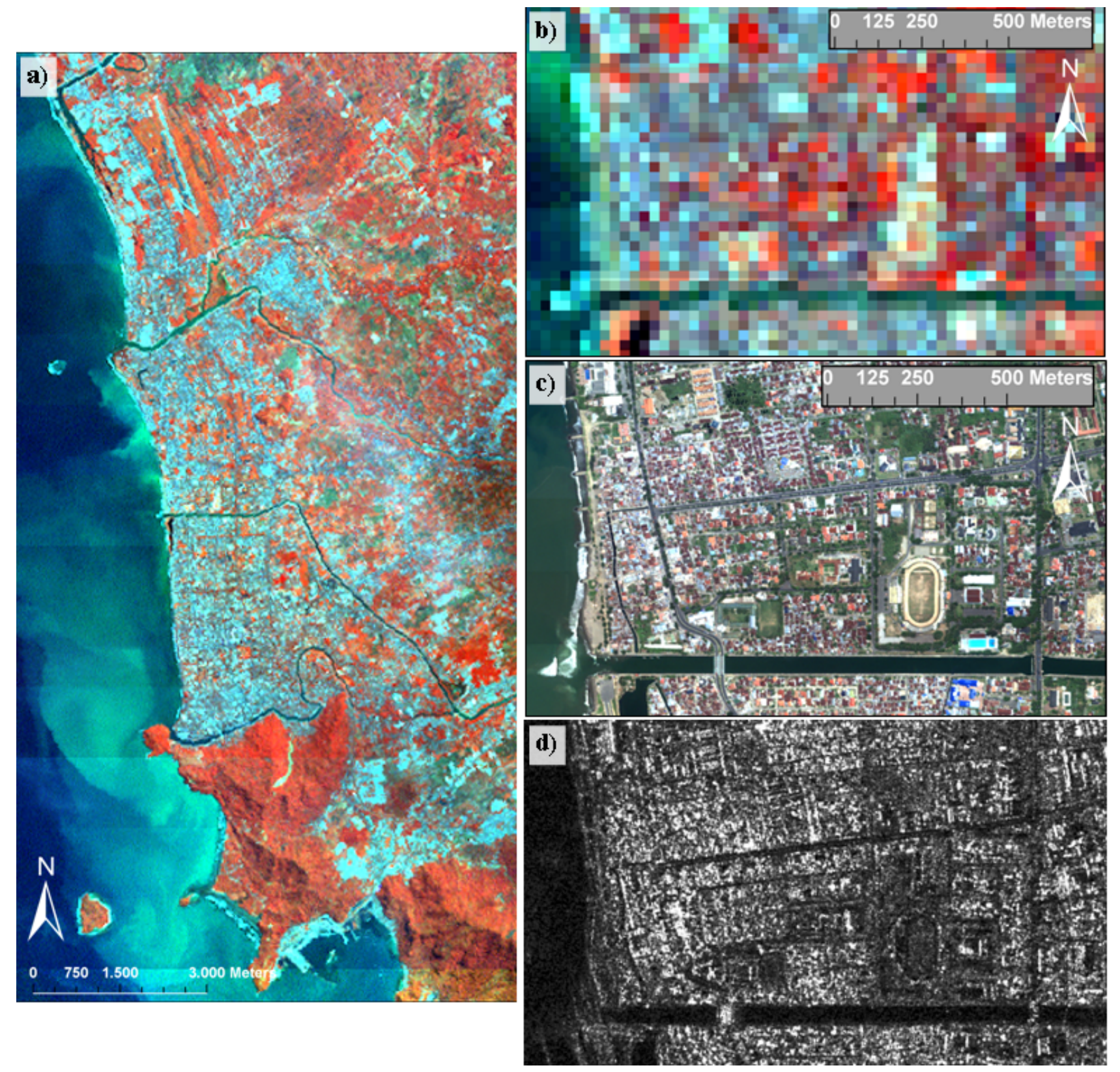

Figure 1. (a) Landsat ETM+ data showing the coastal urban area of Padang from 2001 (b) Detail of the Landsat data (c) Ikonos data from the year 2005 (d) TerraSAR-X stripmap data from 2009

As additional external data sets we integrate in our analysis census data from the year 2000 (BPS, 2000). These data contain population information on district level for the city of Padang. The districts do not represent physically homogeneous units within the urban landscape, but artificial boundaries often enclosing large areas of more than $10 \mathrm{~km}^{2}$.

\section{METHODOLOGY}

Based on the manifold available data sets we give an overview on the various methods used and developed; starting from broad-scale analysis on urban footprint level to fine-scale analysis on individual building level. In addition the external data sets are integrated for interdisciplinary value-adding assessing time-dependent population distribution. 


\subsection{Broad-scale analysis}

We developed two different land cover classification methods extracting the classes 'urbanized areas', 'non-urbanized areas' and 'water' was performed separately on all individual images from Landsat and TerraSAR-X. The main goal is to identify the urban built-up areas to measure the changes of extent, directions, speed and pattern of the urban footprint over the time interval. For that purpose the classification methodology is based on an object-oriented hierarchical approach (Taubenböck, 2008; Thiel et al, 2008a). The object-oriented, fuzzy-based methodology was implemented to combine spectral features with shape, neighbourhood, context and texture features. The classification methodology of Landsat data is mainly based on the spectral capabilities of the sensor. The seven spectral bands as well as indices like NDVI are involved to separate water bodies or vegetation areas from urbanized space. SAR data, however, only provide a single wave length. Consequently, spectral information is rare compared to optical data and it is more difficult to extract precise information from SAR data (Esch et al. 2009). As seen in figure $1 \mathrm{~d}$ settlement areas are characterized by numerous bright scatterers in the intensity image. In order to create a SAR-based settlement mask the classification of urban area starts with the identification of sure urban structures indicated by the high backscattering of corner reflectors. The first classification step aims at the identification of distinct urban point scatterers (UPS) which are characterized by a very high intensity and a very high speckle divergence - features which almost exclusively appear in the context of backscatter from man-made structures. These reflectors are used as seed points (Breunig et al, 2009, Thiel et al, 2008b). Assuming that all settlements feature clusters of UPS the analysis is subsequently focused on the neighbourhood of the UPS. Subsequently, region-growing is implemented for a detection of ambiguous built-up areas. Post classification comparison of the separate urban footprint results for the individual time steps was found to be the most accurate procedure and presented the advantage of indicating the nature of the changes (Mas, 1999). A comparative analysis of land cover classifications for the available times performed independently was therefore implemented to monitor and analyze the land cover changes. Pixelwise change detection was implemented checking the land cover classes individually of the available years. Figure 2 shows the expanding urban footprint of Padang over time since 1989 using multisensoral remotely sensed data. 


\subsection{Fine-scale analysis}

\subsubsection{3-D city model}

We developed an urban land cover classification methodology applied on a high resolution Ikonos image to derive areawide and up-to-date knowledge on the urban environment with highest geometric and thematic detail. The developed methodology is a fixed framework with modular sub-procedures (Taubenböck, 2008). Various input data feature different spectral conditions as well as different structural urban characteristics. Therefore stable transferability is subject to adjustments in this regard. Thus, the main goal is an interactive and individual control of single modules within a clearly arranged and chronological workflow for the possibility of specific and systematic adjustments. This includes initialization or non-consideration of various sub-procedures as well as adjustments on classification features. Under the fixed chronological and structural framework, the interactive modular processes enable a fast and stable transfer on any urban environment in the world. The basic idea is a stepwise procedure of a chronological workflow. Two main modules were implemented: segmentation (1) and classification (2):

(1) The segmentation methodology has been presented by (Esch et al., 2005). It contains an optimization procedure to achieve typical real world segments in one single level. Recapitulating, the concept contains a basic segmentation level and an optimization level with a higher scale parameter. Whenever the sub-object in the basic level shows significant spectral difference to the super-object of the optimization level the particular segment becomes cut out. Thus, this segment stays exact the same shape as in the basic level, while segments with no significant spectral difference to the super-object get merged. This procedure is iteratively performed with a continuously increasing scale-parameter for the generation of the optimization level. The final output of this approach provides a single, improved segmentation level that features large segments in homogeneous areas whereas small-scale structures and heterogeneous regions are represented by distinctively smaller image objects. This means a coexistence of for example a small and rectangle segment for a roof of a house next to a shapeless large segment for grassland.

(2) The second module with individual accessible sub-procedures contains the classification methodology. It is a multilevel fuzzy-logic based classification approach. The thematic urban land cover classification banks on the segments of

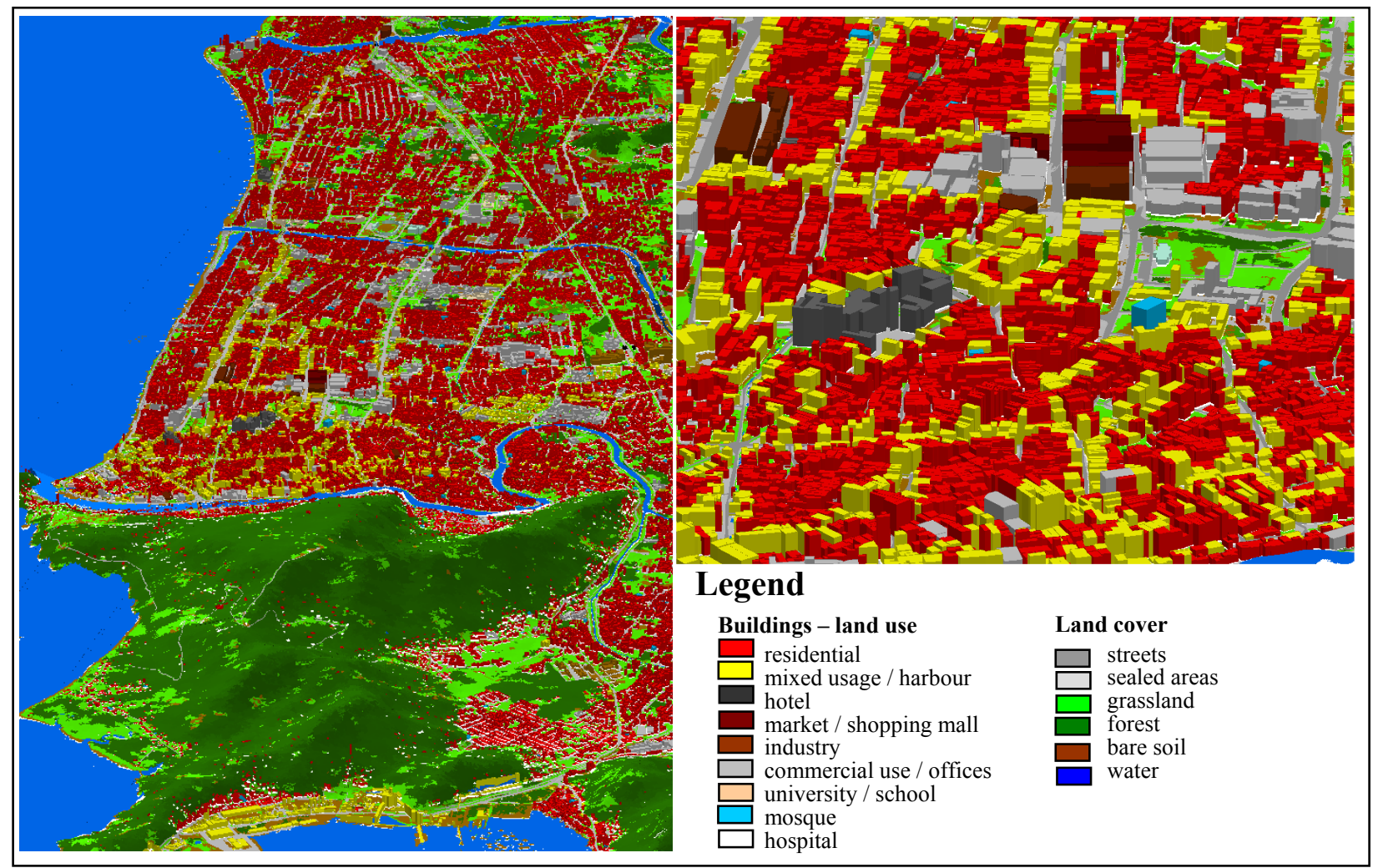

Figure. 3. City model of Padang derived from high resolution satellite data and a digital elevation model (Intermap, 2007) 
the optimization procedure, which represent in the ideal case real world structures. Every class is based on a fuzzy logic (Stolz, 1998) classification methodology. Fuzzy sets are a class with a continuum of grades of memberships (Yager, 1987). Thus, every segment gets a certain probability of class membership according to its particular features. Minimum or maximum functions allow a combination of various features per segment to increase the probability for a particular class membership. The classification methodology is a hierarchical elimination of non built-up areas. The result product displays the basic information to know 'what' is 'where' within the complex urban landscape. The results are eight classes - 'individual houses', 'streets', 'sealed areas', 'grassland', 'trees', 'wetland', 'bare soil', and 'water' - mapping highly detailed urban morphology. Thus, the capabilities of the available remote sensing data sets enable an analysis of the urban morphology on house / block level.

Furthermore we use the land cover classification to calculate physical parameters classifying the physical urban structure. The street network structures the urban landscape into blocks. The ratio of area of buildings to area of the particular block results in built-up density. The building height is derived through an intersection of the building mask with the calculated elevation difference between the Digital Surface Model (DSM) and the Digital Terrain Model (DTM) (Intermap, 2007). Furthermore individual building sizes are calculated and in addition, average building sizes for particular blocks are derived. Utilizing the field work experience in combination with the physical parameters of the individual buildings - size, height, location, alignment and roof type - land use was assessed as an additional feature of every building in the entire urban landscape of Padang. This enables to differentiate between residential, mixed, commercial and industrial usage on a basic level. Thus, the city model even enables a basic localization of economic focal areas. A higher thematic specification was integrated using field work information to localize critical infrastructure like hospitals or schools. The orographic condition of the urban region of Padang utilizing the digital elevation model completes the urban environment of the coastal city. Thus, a three-dimensional city model displays the complex, heterogeneous and fine-scale urban morphology and urban land use in a very detailed manner. This product displays essential basic information to know 'what' is 'where' in the city of Padang (fig. 3).

\subsubsection{Population assessment}

Static urban morphology characterizes an urban agglomeration. But the dynamics of its population also distinguish the urban exposure. We correlate the static element of physical urban structures with the dynamic element of spatial and temporal behaviour of the population by means of the city model and punctual population information on desa (district) level. Basically we use the linear top-down distribution methodology presented by Taubenböck et al. (2007) to resolve the population data from desa onto individual building level. We extend the approach using semantic classification to adjust the interpolation onto different settlement characteristics in physically different urban structures (semantic classes). This information has been provided by field work (Setiadi, 2008; Taubenböck et al., in press).

Using the physical urban morphology parameters a semantic classification has been performed. The idea of semantic classification aims at a first assumed interrelation between physically homogeneous sectors within the complex urban morphology and the socioeconomic characteristics of people residing there. The combination of the area-wide available statistical physical parameters describing the building stock of Padang per sector - built-up density, average house size, average building height, location - enables to identify physically homogeneous areas. This approach for semantic classification is generic, aiming at transferability on any urban area throughout the world with similar physical parameters available. Therefore, we used descriptive statistic values as Quartile (Q1, Q3), Median (Med) or Mean (M) to subdivide the different classes. The six resulting semantic classes are defined by statistical values. An example, we classify 'slums' using built-up density values higher than the third quartile (Q3) of the complete spectrum of the built-up density values classified in Padang. Analogous, the buildings of slums are assumed to be smaller than Q3 and lower than Q1 of the particular spectrum of values classified for the city of Padang. Utilizing these statistical parameters the classification is not affected by cultural or regional characters of urban morphology occurring worldwide. With respect to this methodology, only the semantic nomenclature has to be adjusted on the particular structures and locations (Taubenböck et al., 2009).

Terminology of the semantic classes is based on housing quality and location. The housing quality is assumed to be higher with rising building size or height and lower built-up density. We classify six different semantic classes - 'slums', 'suburbs', 'low class areas' (LC), 'middle class areas' (MC) and 'high class areas' (HC). For every semantic class we assume typical physical conditions. As an example, slum areas are defined by the highest built-up density measured within the urban environment with mostly one storey buildings, with the smallest buildings sizes. With the nomenclature

Proc. of SPIE Vol. $747874781 \mathrm{~J}-6$ 
'slum' the classification by solely physical parameters sets a first hint in the direction of assumed socioeconomic relevance (Taubenböck et al., 2009).

Population data based on a census are provided at a coarse district level (BPS, 2000). The remote sensing results resolve this coarse level down to a geometric level of individual buildings. We provide the number of buildings, their function as well as their size and height at the particular district. Using additional field work data (Setiadi, 2008) different living characteristics per semantic class were identified. Thus, we use a linear top-down distribution technique that distributes total population on living space per house with respect to its function. Furthermore the algorithm takes the different living characteristics per semantic classes into account. At night time the distribution method considers the residential areas as the main residence areas. During day time we assume relocation of people to commercial areas, and thus resulting in a differing spatial population pattern.

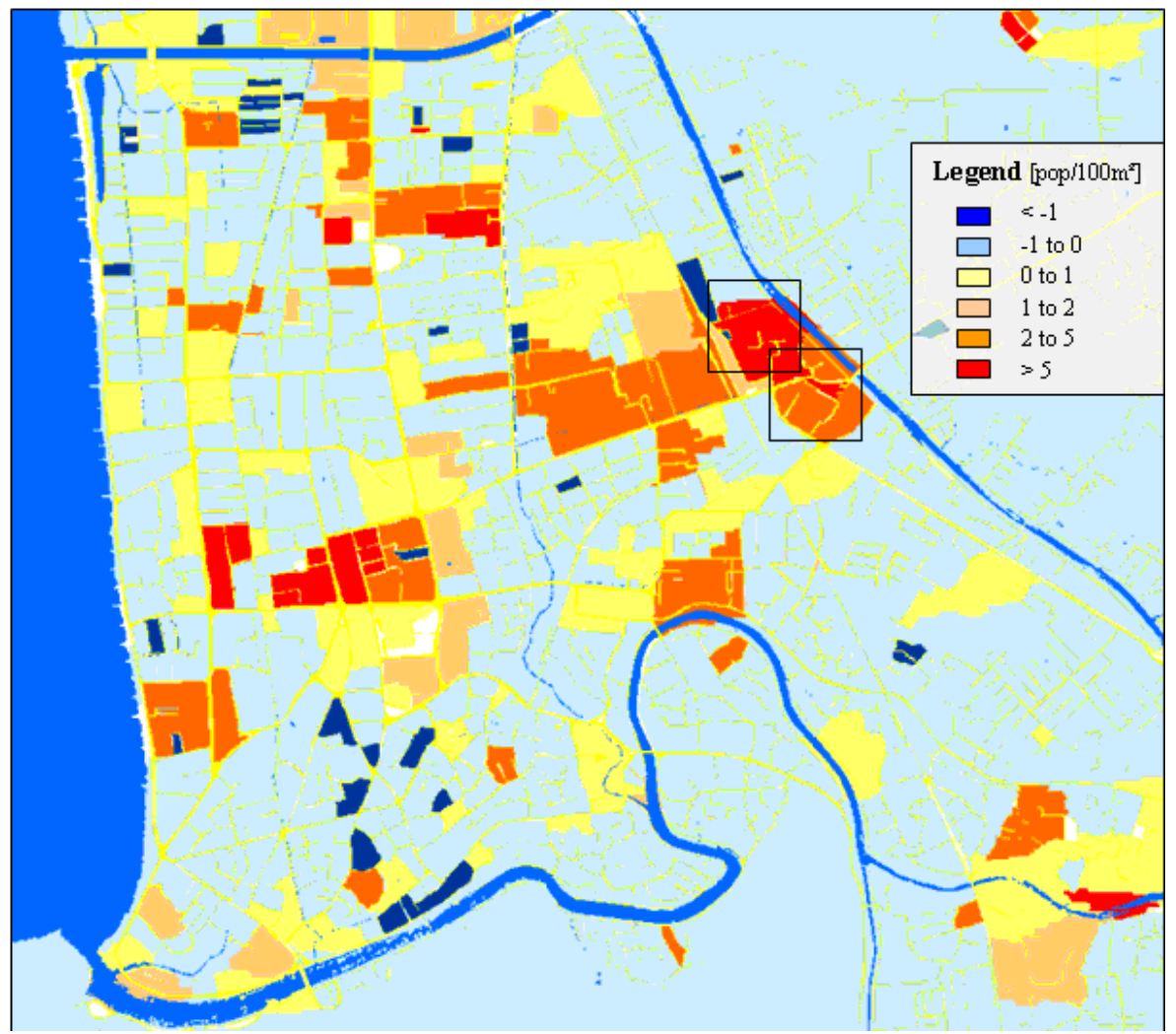

Figure 4. Population streams from nighttime to daytime per $100 \mathrm{~m}^{2}$ of a sector



Industrial tacilities

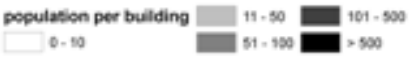

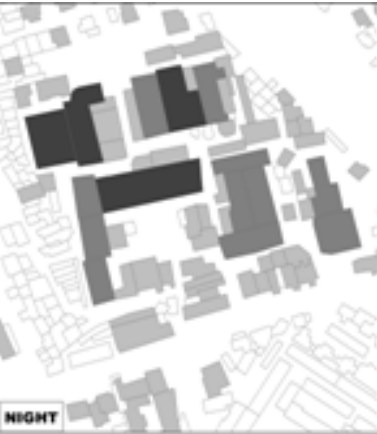

^

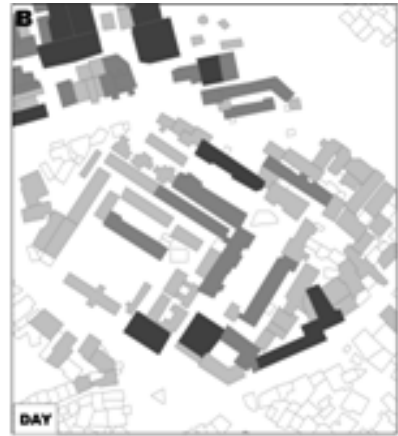

Education facilities

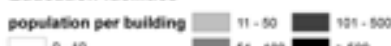

0-10

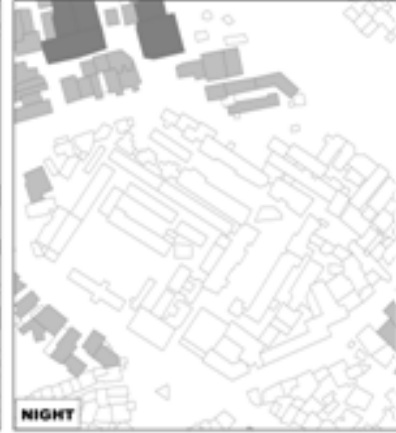

$\AA$

Figure 5. Calculated absolute values of people per building at day and nighttime 
Subsequently the spatial projection of these results on the urban area of Padang enables calculation of the population flux over the course of a day. Thus, we can quantify in dependency of the time of day potentially affected people in case of a tsunami event. It enables us to assess the spatial shift of vulnerability and to analyze different evacuation scenarios. Figure 4 shows areas of population gain and loss at daytime per $100 \mathrm{~m}^{2}$ of the particular sector. On higher resolution, figure 5 shows semantic classes and the results for day- and nighttime population per building. Especially for large nonresidential buildings a greater gradient between day and night populations occurs. Exemplary industrial facilities (a) and educational facilities (b), showing high daytime population and lower respectively no nighttime population, are displayed.

\section{RESULTS AND ACCURACY ASSESSMENT}

The multiscale and multitemporal spatial information derived from multisensoral remote sensing data are selected indicators defining vulnerability of a system, which is in our case the coastal urban system of Padang, Indonesia. The information on spatial urbanization, the 3-D city model and the analysis of the urban structure enable to provide insight into the physical perspective of the vulnerability framework (Taubenböck et al., 2008a). Furthermore the correlation of static urban morphology with the dynamic characteristics of urban populations over time enables to contribute indicators to the demographic perspective of spatial vulnerability. Of course the sample products presented in our study do not fulfil the complete holistic framework of risk, hazards and vulnerability, but provide examples for the capabilities of remote sensing.

The change detection results in an enormous spatial increase of urbanized areas between 1989 until 2000; with $89 \%$ gain the urban landscape is almost doubling its extension. While the bulk of urban expansion is along main infrastructure lines in the suburbs, we observe also densification processes at the urban center and along the coastline, and thus vulnerability is increasing. From 2000 on the urbanization rate is slowing down, but with a spatial increase of urbanized areas until 2009 of $11.2 \%$ is still dynamic. The trend of splinter development in the urban hinterland hints at



Figure 6. Overview and detailed view of safe areas, their accessibility and planned sirens 
uncontrolled urbanization processes. The 3-D city model enables to analyze, from an urban planning point of view, the physical structures of the urbanization process on individual building level. Furthermore, the results allow the quantification of potentially affected structures, their type and their location. In combination with the digital elevation model we extracted potentially safe areas. Figure 6 visualizes safe areas, which have the following conditions: Accessibility by the available street network; areas larger than $10000 \mathrm{~m}^{2}$, to be able to accommodate enough people in a rescue situation; flat area with a land-cover either bare soil or grassland and with an elevation higher than 10 meters above sea level. In addition the 3-D city model supports to analyze appropriate locations for planned sirens (towers) as one way to inform people in the forefront of a tsunami.

The algorithm to distribute the population from district level onto the individual building level resulted in a night population of 498877 for the area of interest consisting of about 88000 buildings (about the area of figure 3). Daytime population resulted in a population gain of about 14000 people suggesting commuters coming from urban hinterland. In contrast, the total population without spatial differentiation of living characteristics is shown. Table 1 specifies the results for the particular semantic classes derived from remote sensing. These results allow a time-dependent assessment of population distribution, and are an important data set to organize evacuation, to plan and manage rescue operations, etc.

Table 1. Results of the extrapolation algorithm to assess population in Padang

\begin{tabular}{|c|c|c|c|}
\hline Classes & day population & night population & $\begin{array}{c}\text { percentage } \\
\text { day/night [\%] }\end{array}$ \\
\hline City area (AOI) & 512658 & 498877 & 103 \\
\hline class 1 - SLUM & 12607 & 20994 & 60 \\
\hline class 2 - LC & 66297 & 58098 & 114 \\
\hline class 3 - MC & 278524 & 235395 & 118 \\
\hline class 4 - SUBURB & 66863 & 84857 & 79 \\
\hline class 5 - HC & 16.380 & 4542 & 361 \\
\hline class 6 - residuals & 71987 & 94991 & 76 \\
\hline Without spatial differentiation (AOI) & 446943 & 428561 & 104 \\
\hline
\end{tabular}

The scientific field of remote sensing can not provide the accuracy of cadastral information. Decision-making before, during and after a hazardous event does not entail cadastral accuracy, but requires quantitative information consistently in the correct dimension. The accuracy assessment proves the capability of remote sensing to fulfil this constraint: An accuracy assessment has been performed by a randomization of 150 checkpoints and a visual verification process resulting in $89.9 \%$ for the urban footprint classification for the year $2009,92.4 \%$ for the urban footprint classification of the year 2000 and $89.1 \%$ for the year 1989. Regarding the high resolution data, the combination of an automatic object-oriented methodology and subsequent manual enhancement provides an accuracy of $97 \%$ for the land cover classification. We assessed the number of stories per building calculating the average of available height points per building resulting in an accuracy of $86.7 \%$.

Table 2. Accuracy assessment of the extrapolation algorithm and comparison of the approach utilizing semantic classes and the approach utilizing a mean value for all buildings

\begin{tabular}{|c|c|c|c|c|}
\hline Classes & Semantic classes & STD & Mean value & STD \\
\hline class 1 - SLUM & $94.21 \%$ & 1.91 & $63.08 \%$ & 2.43 \\
\hline class 2- LMC & $89.48 \%$ & 3.32 & $73.11 \%$ & 3.95 \\
\hline class 3 - MC & $83.82 \%$ & 6.79 & $80.03 \%$ & 6.13 \\
\hline class 4 - SUBURB & $87.56 \%$ & 7.82 & $79.56 \%$ & 9.12 \\
\hline class 5 - HMC & - & - & - & - \\
\hline class 6 - residuals & $74.27 \%$ & 9.41 & $68.09 \%$ & 10.24 \\
\hline Total area (AOI) & $86.73 \%$ & 5.71 & - & - \\
\hline \hline $\begin{array}{c}\text { Without spatial } \\
\text { differentiation (AOI) }\end{array}$ & - & - & $72.12 \%$ & 9.34 \\
\hline
\end{tabular}


Regarding the population assessment accuracy assessment was performed by means of the 500 buildings from the field survey. The assessment shows the compliance of field work results from the questionnaire with the calculated population per house based on the top-down interpolation algorithm. Table 2 presents a comparison between two results: In one section the accuracy is achieved by interpolation using spatial specification by semantic classes as listed. In the other section, the interpolation based on the mean value of living space per person for all classified buildings without further spatial differentiation is presented as comparison. The results clearly reveal that the spatial differentiation by semantic classification increases the accuracy from $72.12 \%$ to $86.73 \%$.

In general, the results provide the spatial basis for interdisciplinary research within the Last-Mile project: e. g. the building mask is used as input parameter for inundation modeling of a potential tsunami (Goseberg et al., 2009) or the derived street network is used for evacuation modelling (Lämmel et al., 2008). Furthermore the 3-D city model is used distribute the survey samples (Setiadi, 2008). Multi-layer analysis allows quantifying and localizing exposed elements of the urban landscape (Taubenböck et al., in press).

\section{CONCLUSION AND OUTLOOK}

This study has demonstrated the powerful contribution of remote sensing for vulnerability analysis in tsunami-prone urban areas. Remote sensing proved to be an independent, area-wide and for the dynamically changing urban areas a necessary up-to-date data source to meet the requirements of urban risk management. The analysis in this study is a combination of automatic classification algorithms and manual enhancement to infer urban morphology characteristics from high resolution satellite data - thus contributing to the physical perspective of vulnerability. In combining results from remote sensing with external data sets, e. g. population sources, interdisciplinary approaches allow for valueadding. In our case, the large amount of field work data enabled reliable assessment of land use as well as living characteristics. Thus, the depth of data is very high, which requires high efforts in time or money in case of adaptation to other cities or regions.

\section{ACKNOWLEDGEMENTS}

The authors would like to thank the DFG/BMBF special Programme "Geotechnologies" - Early Warning Systems in Earth Management. Sponsorship Code: 03G0666A-E. We would also like to thank our partners from Andalas University as well as the provincial and city authorities in the city of Padang, West Sumatra, Indonesia.

\section{REFERENCES}

[1] Barber, B, Tsunami relief. US Agency for International Development. Washington D. C., 28 pp., (2005)

[2] Birkmann, J., Dech, S., Goseberg, N., Lämmel, G., Moder, F., Nagel, K., Oczipka, M., Schlurmann, T., Setiadi, N., Siegert, F., Strunz, G. \& Taubenböck, H., Numerical Last-Mile Tsunami Early Warning and Evacuation Information System. In: International Conference on Tsunami Warning (ICTW), Bali, Indonesia, November 12-14, 2008. pp. 12. (2008)

[3] Borrero, J. C.; Sieh, K.; Chlieh, M. \& Synolakis, C. E., Tsunami inundation modeling for western Sumatra Proceedings of the National Academy of Science of the United States of America, 2006, 103, 19673-19677. PNAS online publication, available at http://www.pnas.org, (2006).

[4] BPS (2000): Population census of the year 2000. Badan Pusat Statistics, Jarkarta, Indonesia.

[5] Breunig, M., Taubenböck, H., Wurm, M. \& Roth, A., Changing urbanity in Istanbul: Analysis of mega city developments using synergistic potentials of multi-temporal SAR and optical data. Proceedings of the URS/URBAN Conference, 20-22 May 2009, Shanghai. (2009).

[6] Esch T., Roth A., Dech S., Robust approach towards an automated detection of built-up areas from high resolution radar imagery. In: Proceedings of the ISPRS WG VII/1 "Human Settlements and Impact Analysis" 3rd International Symposium Remote Sensing and Data Fusion Over Urban Areas (URBAN 2005) and 5th International Symposium Remote Sensing of Urban Areas (URS 2005). Tempe, AZ, USA. March 14 - 16, (2005).

[7] Esch, T., Taubenböck, H., Heldens, W., Thiel, M., Wurm, M., Klein, D., Dech, S., Roth, A., Schmidt, M., Monitoring and assessment of urban environments using space-borne earth observation data - selected 
applications. In: Krek, Rumor, Zlatanova \& Fendel (eds). "Urban and Regional Data Management", Taylor \& Francis Group, London, ISBN 978-0-415-55642-2. pp. 385-398. (2009).

[8] Goseberg, N., Stahlmann, A., Schimmels, S., Schlurmann, T., Highly resolved numerical modeling of tsunami runup and inundation scenario in the city of Padang, West Sumatra. Proc. of the 31st Int. Conference on Coastal Engineering, (2009).

[9] Herrmann, J. \& Bottero A.-G., TerraSAR-X Mission: The New Generation in High Resolution Satellites. - In: Anais XIII Simpósio Brasiliero de Sensoriamento Remoto, Florianópolis, Brasil: 7063-7070. (2007).

[10] Intermap, Product Handbook \& Quick Start Guide, Intermap Technologies, Standard Edition v4.0; (2007).

[11]Lämmel, L., Rieser, M., Nagel, K., Taubenböck, H., Strunz, G., Goseberg, N., Schlurmann, T., Klüpfel, H., Setiadi, N., and Birkmann, J., Emergency Preparedness in the case of a Tsunami - Evacuation Analysis and Traffic Optimization for the Indonesian city of Padang, Proc. of the $4^{\text {th }}$ International Conference on Pedestrian and Evacuation Dynamics, Wuppertal, Germany. (2008).

[12] Last-Mile Project (2009). www.last-mile-evacuation.de (2009).

[13] Leitmann, J., Cities and Calamities: Learning from Post-Disaster response in Indonesia. In: Journal of Urban Health: Bulletin of the New York Academy of Medicine, Vol. 84, No.1. (2007).

[14] Mas, J.-F., Monitoring land-cover changes: a comparison of change detection techniques. International Journal of Remote Sensing, vol. 20, No. 1, pp. 139-152. (1999).

[15] Rastogi, B. K., Jaiswal, R. K., A Catalog of Tsunamis in the Indian Ocean. In: Science of Tsunami Hazards 25(3): 128-143. (2006).

[16] Setiadi, N., WP 1000: Socio-Economic Vulnerability Assessment - Numerical Last-Mile Tsunami Early Warning and Evacuation System. Presentation for the Status Meeting Geotechnologies, October 8, 2008, Osnabrück. (2008).

[17] Stolz, R., Die Verwendung der Fuzzy Logic Theorie zur wissensbasierten Klassifikation von Fernerkundungsdaten, Münchner Geographische Abhandlungen, Reihe B. Geobuch Verlag, München. (1998).

[18] Taubenböck, H., Goseberg, N., Setiadi, N., Lämmel, G., Moder, F., Oczipka, M., Klüpfel, H., Wahl, R., Schlurmann, T., Strunz, S., Birkmann, J., Nagel, K., Siegert, F., Lehmann, F., Dech, S., Gress, A., Klein, R. LastMile' preparation to a potential disaster - Interdisciplinary approach towards tsunami early warning and an evacuation information system for the coastal city of Padang, Indonesia. In: Natural Hazards and Earth System Sciences (NHESS), 9; (in press).

[19] Taubenböck, H., Wurm, M., N. Setiadi, N. Gebert, A. Roth, G. Strunz, J. Birkmann \& S. Dech, Integrating Remote Sensing and Social Science - The correlation of urban morphology with socioeconomic parameters. In: Proceedings of the URS/URBAN Conference, 20-22 May 2009, Shanghai. China. pp. 7. (2009).

[20] Taubenböck, H., Vulnerabilitätsabschätzung der erdbebengefährdeten Megacity Istanbul mit Methoden der Fernerkundung. $\mathrm{PhD}$ Thesis. University of Würzburg, p. 178. http://www.opus-bayern.de/uniwuerzburg/volltexte/2008/2804/, (2008).

[21] Taubenböck, H., Post, J., Roth, A., Zosseder, K., Strunz, G. and Dech, S., A conceptual vulnerability and risk framework as outline to identify capabilities of remote sensing. In: Natural Hazards and Earth System Sciences. vol. 8, no. 3, pp. 409-420. http://www.nat-hazards-earth-syst-sci.net/8/409/2008/nhess-8-409-2008.html, (2008).

[22] Taubenböck, H., Roth, A. \& Dech, S., Linking structural urban characteristics derived from high resolution satellite data to population distribution. In: Urban and Regional Data Management. In: Coors, Rumor, Fendel \& Zlatanova (Hrsg.). Taylor \& Francis Group, London, ISBN 978-0-41544059-2. S. 35-45. (2007).

[23] Thiel, M., Esch, T. \& Dech, S., Object-oriented detection of settlement areas from TerraSAR-X data. Proceedings of the EARSeL Joint Workshop: Remote Sensing: New Challenges of high resolution. (Eds., Carsten Jürgens). ISBN 978-3-925143-79-3. pp. 242-248. Bochum, Germany. (2008a).

[24] Thiel, M., Esch, T., Wurm, M., Taubenböck, H. \& Dech, S., Classification of urban environments with TerraSAR-X and ALOS-PALSAR data. In: Proceedings of SPIE-Europe (International Society for Optical Engineering) Conference, Cardiff, Wales. (2008b).

[25] Yager, R., Fuzzy sets and applications, selected papers, by L. Zadeh, New York. (1987). 